\title{
Secondary aerosol formation from photochemical aging of aircraft exhaust in a smog chamber
}

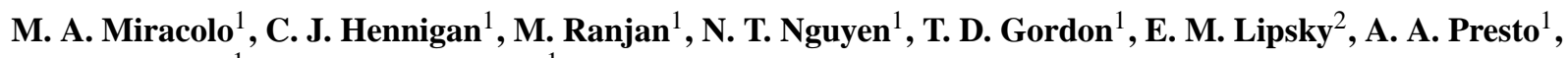 \\ N. M. Donahue ${ }^{1}$, and A. L. Robinson ${ }^{1}$ \\ ${ }^{1}$ Center for Atmospheric Particle Studies, Carnegie Mellon University, Pittsburgh, PA, 15213, USA \\ ${ }^{2}$ Penn State Greater Allegheny, McKeesport, PA, 15123, USA
}

Received: 3 November 2010 - Published in Atmos. Chem. Phys. Discuss.: 15 November 2010

Revised: 10 April 2011 - Accepted: 12 April 2011 - Published: 5 May 2011

\begin{abstract}
Field experiments were performed to investigate the effects of photo-oxidation on fine particle emissions from an in-use CFM56-2B gas turbine engine mounted on a $\mathrm{KC}$ 135 Stratotanker airframe. Emissions were sampled into a portable smog chamber from a rake inlet installed one-meter downstream of the engine exit plane of a parked and chocked aircraft. The chamber was then exposed to sunlight and/or UV lights to initiate photo-oxidation. Separate tests were performed at different engine loads $(4,7,30,85 \%)$. Photooxidation created substantial secondary particulate matter (PM), greatly exceeding the direct PM emissions at each engine load after an hour or less of aging at typical summertime conditions. After several hours of photo-oxidation, the ratio of secondary-to-primary PM mass was on average $35 \pm 4.1$, $17 \pm 2.5,60 \pm 2.2$, and $2.7 \pm 1.1$ for the $4,7,30$, and $85 \%$ load experiments, respectively. The composition of secondary PM formed strongly depended on load. At $4 \%$ load, secondary PM was dominated by secondary organic aerosol (SOA). At higher loads, the secondary PM was mainly secondary sulfate. A traditional SOA model that accounts for SOA formation from single-ring aromatics and other volatile organic compounds underpredicts the measured SOA formation by $\sim 60 \%$ at $4 \%$ load and $\sim 40 \%$ at $85 \%$ load. Large amounts of lower-volatility organic vapors were measured in the exhaust; they represent a significant pool of SOA precursors that are not included in traditional SOA models. These results underscore the importance of accounting for atmospheric processing when assessing the influence of aircraft emissions on ambient PM levels. Models that do not account for this processing will likely underpredict the contribution of aircraft emissions to local and regional air pollution.
\end{abstract}

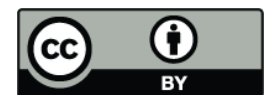

Correspondence to: A. L. Robinson (alr@andrew.cmu.edu)

\section{Introduction}

Many airports are located in areas with elevated air pollution levels and recent studies report that aircraft operations can contribute significantly to this pollution (Carslaw et al., 2006; Unal et al., 2005; Dodson et al., 2009; Yu et al., 2004; Hu et al., 2009). In order to quantify the impacts of airports on ground-level air quality, there is a need for improved understanding of both aircraft emissions and how those emissions evolve in the atmosphere. In this paper, we focus on the contribution of aircraft emissions to ambient fine particle mass (PM).

Aircraft exhaust contributes to ambient PM levels in two ways - primary PM that is directly emitted from aircraft and secondary PM that is formed in the atmosphere as a result of photo-oxidation of gaseous emissions. Numerous studies have investigated primary PM emissions from aircraft (Agrawal et al., 2008; Petzold and Schröder, 1998). The magnitude and composition of these emissions strongly depend on engine load. Furthermore, as the exhaust is diluted and cooled downstream of an engine, the particle size and composition can evolve significantly (Onasch et al., 2009). The experiments described in this manuscript use a smog chamber to investigate the effects of photooxidation on aircraft exhaust over longer atmospherically relevant timescales.

Recent experiments have demonstrated that oxidative aging of exhaust from combustion systems, including dilute diesel exhaust (Chirico et al., 2010) and woodsmoke (Grieshop et al., 2009b), results in substantial formation of secondary organic aerosol (SOA). It is likely that the same is true of aircraft exhaust. Aircraft emit significant quantities of volatile organic compounds (VOCs), including known SOA precursors such as benzene and toluene (Anderson et al., 2006; Slemr et al., 1998; Agrawal et al., 2008; Spicer et al., 1999; Herndon et al., 2006, 2009). The magnitude

Published by Copernicus Publications on behalf of the European Geosciences Union. 
and composition of VOC emissions depend strongly on load, with much higher emissions at low engine loads. Wood et al. (2008) also found enhanced levels of $\mathrm{HO}_{\mathrm{x}}$ in exhaust from idling engines. Therefore, the potential for secondary PM production should be significant. However, few studies have experimentally investigated the effects of photochemistry on aircraft emissions. Spicer et al. (1999) performed ozone reactivity experiments with emissions at idle power, concluding that the idle emissions were very reactive for ozone formation. However, that study did not investigate the potential for secondary PM formation.

In this paper, we present results from smog chamber experiments of secondary PM formation from the photo-oxidation of aircraft exhaust. We describe the magnitude and composition of secondary PM formed at different engine loads. The data are then used to evaluate the performance of a traditional SOA model. The paper concludes with a discussion of the relative importance of primary PM emissions versus secondary PM production. Better understanding of the evolution of PM emissions should improve models that predict the influence of these emissions on urban and regional air quality. Details on the composition and partitioning behavior of primary PM emissions from these experiments are presented in a companion paper (Presto et al., 2011).

\section{Experimental methods}

\subsection{Experimental setup}

Experiments were performed to characterize the effects of photo-oxidation on the emissions from a CFM56-2B gas turbine engine mounted on a KC-135 Stratotanker airframe. The CFM56 is one of the most widely used family of engines in the world, powering more than 8000 commercial and military aircraft (www.cfm56.com). The experiments were conducted in collaboration with the Pennsylvania Air National Guard 171st Air Refueling Wing at the Pittsburgh International Airport during a two-week period in July 2009.

Separate experiments were performed at different loads while the aircraft was parked and chocked. A summary of the experiments is listed in Table S1 in the Supplement. Test points were set based on fan speed (N1) to correspond to different engine thrusts including climb out (85\% of maximum thrust), approach (30\% of maximum thrust), idle (7\% of maximum thrust), and minimum engine load ( $4 \%$ of maximum thrust). After start up, the engine was run for approximately five minutes at low load (4\%), allowing some time for warm-up, before the test point was set. Sampling began several minutes after the test point was set. Time-series of fan speed and exhaust gas temperature for each engine run are plotted in the Supplement (Fig. S1). The engine exhaust gas temperature was stable throughout each experiments. In high load experiments, the engine oil temperature slowly increased throughout the sampling period. The engine was op- erated on standard JP-8 fuel; composition data for the fuel is listed in Table S3 in the Supplement.

A schematic of the experimental setup is shown in Fig. 1. Details of the sampling configuration are described in detail elsewhere (Presto et al., 2011). Briefly, emissions were sampled through a rake inlet installed one-meter downstream of the engine exit plane. The rake consisted of three equally spaced inlets, with one centered on the oil vent and the other two installed $7.6 \mathrm{~cm}$ above and below the center inlet. The emissions were transferred into a $7 \mathrm{~m}^{3}$ Teflon smog chamber through a $21-\mathrm{m}$ stainless steel transfer line that was electrically heated to $150^{\circ} \mathrm{C}$ to minimize thermophoretic and condensation losses. Particle losses in the transfer line were characterized in separate experiments using dried sodium chloride aerosols. The transfer line efficiency was largely independent of size in the range of 50-400 nm (within the uncertainty of the measurement). The smog chamber data were corrected for transfer line losses; an average measured penetration efficiency of $85 \%$ was used to correct the primary EC data, while $100 \%$ efficiency was assumed for organics, which assumes the OA is evaporated in the transfer line. It is reasonable to assume $100 \%$ of the primary OA is evaporated in the transfer line at $150^{\circ} \mathrm{C}$ because our volatility measurements with a thermodenuder indicate $75 \%$ of the primary $\mathrm{OA}$ is evaporated at $80^{\circ} \mathrm{C}$ (Fig. 9). The exhaust was pushed into the portable chamber using two ejector dilutors (Dekati, model DI-100) connected in parallel to the end of the transfer line; these dilutors were operated at $150^{\circ} \mathrm{C}$ with clean (HEPA and activated carbon filtered) and dry air. All surfaces in contact with the exhaust upstream of the smog chamber were maintained at $150^{\circ} \mathrm{C}$.

The smog chamber was a $7 \mathrm{~m}^{3}$ Teflon bag suspended on an open metal frame. Before each experiment, the chamber was cleaned by flushing with HEPA and activated carbon filtered air. Prior to adding exhaust, the chamber was one-half to three-quarters filled with clean air at ambient temperature. Upon entering the chamber, the exhaust rapidly mixed with the air inside the chamber, reducing the exhaust temperature to near ambient conditions. Exhaust was added to the chamber for five to thirty minutes while the engine was operated at steady-state conditions; initial particle mass concentrations inside the chamber ranged between 1 and $10 \mu \mathrm{g} \mathrm{m}^{-3}$. After filling, the dilution ratio of the exhaust inside the chamber relative to the engine exit plane was between 43-127 (mean of 88), which corresponds to about $100 \mathrm{~m}$ downstream of the engine exit plane. During filing, the chamber was covered to prevent exposure to sunlight. Prior to photo-oxidation, the average initial chamber temperature was $23 \pm 2.5^{\circ} \mathrm{C}$ with a relative humidity of $14.7 \pm 3.8 \%$ across the set of experiments. Since the portable smog chamber was located outside, it was subject to ambient temperature changes. The chamber temperature increased, on average, by $4.4{ }^{\circ} \mathrm{C}$ during the photo-oxidation phase of the experiment.

After filling, we characterized the primary emissions inside the dark chamber for approximately one hour before 


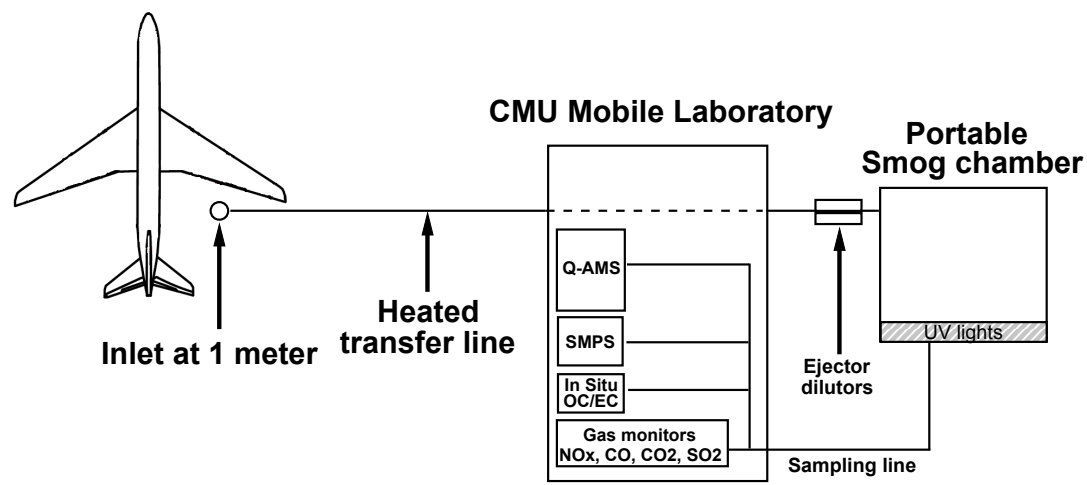

Fig. 1. Schematic diagram of experimental setup for the photo-oxidation experiments. Emissions were sampled from a KC-135 Stratotanker inboard engine through an inlet installed one-meter downstream of the engine exit plane. Emissions were transferred into a portable smog chamber and monitored throughout the experiment with instruments onboard the CMU Mobile Laboratory. The figure is not-to-scale; the smog chamber and mobile laboratory were located about 3-m from the tip of the wing.

exposing the chamber to light (initiating photo-oxidation). Photo-oxidation was initiated either by turning on banks of UV lights (Model F40BL UVA, General Electric) and/or removing the cover to expose the chamber to sunlight.

\subsection{Instrumentation}

A suite of real-time instrumentation was used to monitor the evolution of the gas- and particle-phase pollutants inside the smog chamber. Particle-phase measurements included a Scanning Mobility Particle Sizer (DMA Model 3081, CPC Model 3772, TSI Inc.), an in-situ OC/EC analyzer (Sunset Laboratories) to measure organic and elemental carbon (OC and EC) concentrations and a seven channel Aethalometer (Magee Scientific, Model AE-31) to measure black carbon (BC). Particle size and composition distributions of nonrefractory mass were monitored using a quadrople Aerosol Mass Spectrometer (AMS).

Aerosol volatility was measured using a thermodenuder (TD) system based on the design of Huffman et al. (2008). The aerosol from the chamber was alternately sampled through the TD or a bypass line maintained at ambient temperature $\left(25^{\circ} \mathrm{C}\right)$ every $15 \mathrm{~min}$ using the AMS and SMPS. The TD system was operated with two different temperature programs. Prior to photo-oxidation, the primary aerosol was characterized at 40,60 and $80^{\circ} \mathrm{C}$. During photo-oxidation, the TD was held at $60^{\circ} \mathrm{C}$. After photo-oxidation, the aged aerosol was characterized at 40,60 and $80^{\circ} \mathrm{C}$. The centerline residence time of the heated section was $18.6 \mathrm{~s}$ at ambient temperature.

Measured gas-phase species included $\mathrm{CO}_{2}$ (LI-820, LiCor Biosciences), CO (Model 300A, API-Teledyne), $\mathrm{NO}_{\mathrm{x}}$ (Model 200A, API-Teledyne), $\mathrm{SO}_{2}$ (Model 100E, APITeledyne), and $\mathrm{O}_{3}$ (Model 400E, API-Teledyne). Samples were also collected in SUMMA canisters for offline GC-MS analysis of 94 volatile organic gases; a complete list of mea- sured VOCs is provided in the Supplement (Presto et al., 2011).

\subsection{Data analysis}

Emission data are reported as fuel based emission factors. Emission factors were calculated using a mass balance on fuel carbon:

$\mathrm{EF}=\frac{[P]}{\left[\Delta \mathrm{CO}_{2}\right]} \times \frac{\mathrm{MW}_{\mathrm{CO}_{2}}}{\mathrm{MW}_{\mathrm{C}}} \times C_{\mathrm{f}}$

where $[P]$ is the measured pollutant concentration inside the chamber, $\left[\Delta \mathrm{CO}_{2}\right]$ is the background corrected $\mathrm{CO}_{2}$ concentration in the chamber, $\mathrm{MW}_{\mathrm{CO}_{2}} / \mathrm{MW}_{\mathrm{c}}$ is the ratio between the molecular weights of $\mathrm{CO}_{2} / \mathrm{C}$, and $C_{\mathrm{f}}$ is the carbon content of the fuel. The carbon content of the fuel was 0.86 by mass (Table S3 in the Supplement). Equation (1) assumes that all of the fuel carbon is emitted as $\mathrm{CO}_{2}$; in practice a minor amount $(<0.5 \%)$ of fuel carbon was emitted as other species, especially at lower loads.

The AMS data were interpreted using the fragmentation table of Allan et al. (2004). The contribution of gas-phase $\mathrm{CO}_{2}$ to the $m / z, 44$ signal was corrected using the measured $\mathrm{CO}_{2}$ concentrations. Maximum $\mathrm{CO}_{2}$ levels in the chamber after exhaust injection ranged from 625 to 1190 ppmv. $\mathrm{CO}_{2}$ levels remained constant throughout a photo-oxidation experiment $(<1 \%$ change over several hours).

For the $4 \%$ engine load experiments, there was significant organic particle signal at $\mathrm{m} / z 28\left(\mathrm{CO}^{+}\right)$in addition to the large air beam signal $\left(\mathrm{N}_{2}^{+}\right)$. The default fragmentation table in the unit mass resolution (UMR) analysis software assigns zero organic signal at $\mathrm{m} / \mathrm{z} 28$ (Allan et al., 2004). However, recent analysis has shown that the organic contribution at $\mathrm{m} / \mathrm{z} 28$ can be significant for both ambient (Aiken et al., 2008; Zhang et al., 2005) and chamber data (Grieshop et al., 2009a). The organic signal at $m / z, 28$ was treated in a similar manner as Grieshop et al. (2009a) for all the $4 \%$ load 
experiments. Briefly, an estimate of the organic particle signal is obtained by subtracting the gas-phase signal from the total signal at $m / z, 28$ and then calculating an organic equivalent mass for the particle signal. The baseline for the signal at $\mathrm{m} / \mathrm{z} 28$ was determined by using a linear fit between HEPAfiltered chamber air samples taken at the beginning and end of the experiments. For the $4 \%$ load experiments, the contribution of particle signal at $\mathrm{m} / \mathrm{z} 28$ was on average $10 \%$ of the total OA. There was no particle-signal at $\mathrm{m} / \mathrm{z} 28$ in the experiments performed at higher loads $(7,30,85 \%)$.

The SMPS data were converted to particle mass assuming spherical particles and using measurements of aerosol composition from the AMS and Aethalometer to estimate particle density. The spherical particle assumption is robust at lower loads where the particle mass is dominated by organics and there is very substantial SOA formation. At high load $(85 \%)$ there is substantial EC in the primary emissions. The concentration of organic and sulfate mass was determined by scaling the total particle volume concentrations measured with the SMPS with measured composition ratios from the AMS between organics and sulfate. We assumed that the EC component has a density of $2.0 \mathrm{~g} \mathrm{~cm}^{-3}$, the sulfate component has a density of $1.8 \mathrm{~g} \mathrm{~cm}^{-3}$ and the organic component has a density of $1.1 \mathrm{~g} \mathrm{~cm}^{-3}$. An organic aerosol density of $1.1 \mathrm{~g} \mathrm{~cm}^{-3}$ was estimated with AMS and SMPS data at $4 \%$ load using the method of DeCarlo et al. (2004) and the same density was assumed for all loads.

To estimate secondary aerosol formation, the chamber data must be corrected for loss of particles and semivolatile vapors to the smog chamber walls (Weitkamp et al., 2007). While accounting for the loss of particles to the chamber walls is relatively straightforward, losses of condensable vapors to the chamber walls can introduce significant uncertainty to the wall loss correction (Matsunaga and Ziemann, 2010). These corrections were made following the approach of Weitkamp et al. (2007). Briefly, the change in the suspended particle mass in the chamber $\left(C_{\text {sus }}\right)$ is given by:

$$
\frac{d}{d t}\left[C_{\text {sus }}\right]=-k_{\mathrm{w}} C_{\text {sus }}+\dot{P}_{\text {sus }}
$$

where $k_{\mathrm{w}}$ is the first order wall loss rate constant and $\dot{P}_{\text {sus }}$ is the production rate of SOA on the suspended particles. The change in mass on the walls of the chamber $\left(C_{\text {wall }}\right)$ is given by:

$\frac{d}{d t}\left[C_{\text {wall }}\right]=k_{\mathrm{w}} C_{\text {sus }}+\dot{P}_{\text {wall }}$

where $\dot{P}_{\text {wall }}$ is the loss rate of condensable vapors to the walls. A first-order wall loss rate was estimated using the measured decay of black carbon (non-reactive) as measured by the Aethalometer and/or the measured decay of primary PM mass before the lights are turned on.

To determine the wall-loss corrected concentration in the chamber, we solve for the production rate of new mass in the chamber $\dot{P}_{\text {wall }}+\dot{P}_{\text {sus }} . \dot{P}_{\text {sus }}$ is calculated by numerically integrating Eq. (2) using the time-series of SMPS measurements of suspended mass concentrations. The production rate on the walls is calculated by relating particle mass on the walls to the particle mass in suspension:

$\dot{P}_{\text {wall }}=\dot{P}_{\text {sus }}\left(\frac{\omega C_{\text {wall }}}{C_{\text {sus }}}\right)$

We consider two limiting cases for calculating production rate to the walls: when the condensable products only partition to the suspended particles $(\omega=0)$ and when the material lost to the walls remains completely in equilibrium with the gas phase $(\omega=1)$. The sulfate mass in the chamber was corrected using the case of $\omega=0$ while the organic mass in the chamber is corrected using the case of $\omega=0$ and $\omega=1$.

Aerosol volatility is expressed in terms of a mass fraction remaining (MFR). The MFR is defined as the ratio of the AMS organic aerosol concentration measured downstream of the TD to that measured downstream of the bypass line $\left(C_{\mathrm{BP}}\right)$ :

$\mathrm{MFR}=\frac{C_{\mathrm{TD}}}{C_{\mathrm{BP}}}$

In this work, MFRs were calculated for both total AMS OA concentrations and individual AMS mass fragments, such as $\mathrm{m} / \mathrm{z}, 44$ and 57 . For the temperatures used in this study particles losses in the TD are small $(<10 \%)$ and no corrections were made for these losses (Huffman et al., 2008; An et al., 2007).

\subsection{SOA modeling}

The contribution of known SOA precursors to SOA formation was quantified using the SOA model SOAM-II as implemented by Weitkamp et al. (2007), which is based on the work of Odum et al. (1996). For each precursor, SOAM-II uses yields and partitioning coefficients for a set of lumped condensable products that have been derived from experiments conducted in laboratory smog chambers. For this work, we have updated SOAM-II to include additional precursors and the latest yield data. This version of SOAM-II uses the low- and high- $\mathrm{NO}_{\mathrm{x}}$ volatility basis set SOA yield parameterizations of Murphy et al. (2009) and recently published yield data for aromatic precursors such as xylenes and benzene (Ng et al., 2007), toluene (Hildebrandt et al., 2009), and naphthalene (Chan et al., 2009).

SOAM-II was implemented in a box model that tracks the concentration and partitioning of condensable products inside the smog chamber. The model accounts for loss of condensable product to chamber walls, using the framework describe above. The partitioning of condensable products is calculated using absorptive partitioning theory (Odum et al., 1996), assuming that each products forms an ideal solution with the entire organic aerosol mass. 
In this work, SOAM-II accounts for oxidation of 78 SOA precursors, including alkanes, alkenes, and aromatics. A complete list of precursors is provided in Table S4 in the Supplement. The initial concentrations in the chamber for VOC precursors are based on the SUMMA canisters data. The decay of each precursor is estimated based on $\mathrm{OH}$ concentrations inferred from the measured decay of $\mathrm{SO}_{2}$ and published kinetic data.

\section{Results}

\subsection{Production of secondary aerosol}

Figure 2 shows time-series of gas- and particle-phase concentrations measured inside the smog chamber during a typical experiment with exhaust from $4 \%$ engine load. Each experiment can be divided into three different periods which are labeled on the top of Fig. 2: bag filling, during which exhaust was added to the chamber; primary emission characterization, during which chamber contents were characterized in the dark; and photo-oxidation, during which the chamber was exposed to UV light.

To provide context for the effects of photo-oxidation, data on the primary (unaged) emissions collected from the smog chamber during the primary characterization period and using a portable dilution sampler connected to the transfer line are summarized in Table 1. These data are described in detail by Presto et al. (2011). Total PM mass emissions were highest at low (4\%) and high (85\%) load and lower at intermediate loads $(7 \%, 30 \%)$. PM mass emissions at $4 \%$ load are dominated by organics, while at $85 \%$ load elemental carbon is dominant. Although primary PM mass and organic carbon (OC) emissions factors are listed in Table 1, Presto et al. (2011) demonstrates that a large fraction of these emissions are semivolatile, which means that one cannot define a single PM emission factor (Robinson et al., 2010). The emission factors listed in Table 1 are for average ambient conditions. Trends in the emissions of single-ring aromatics are shown in Fig. 7b; these are important SOA precursors. The emissions of single-ring aromatics are highest at $4 \%$ load and fall sharply with increased engine power. The emissions of aromatics at $85 \%$ load are similar to those at $7 \%$, and only a factor of 4 smaller than emissions at $4 \%$ load. The magnitude and trends of the primary emissions data of this aircraft are similar to results from previous studies on the CFM56 family of engines (Agrawal et al., 2008; Onasch et al., 2009; Kinsey et al., 2010).

Figure 2a plots measured $\mathrm{NO}, \mathrm{CO}_{2}, \mathrm{CO}, \mathrm{SO}_{2}$, and $\mathrm{O}_{3}$ data inside the smog chamber. Concentrations of primary species $\left(\mathrm{NO}, \mathrm{CO}_{2}, \mathrm{CO}, \mathrm{SO}_{2}\right.$ ) increased during the bagfilling phase of the experiment as exhaust was added to the chamber. In the experiment shown in Fig. 2, the concentration of $\mathrm{CO}_{2}$ increased from approximately 400 to $950 \mathrm{ppmv}$ and then remained constant throughout the
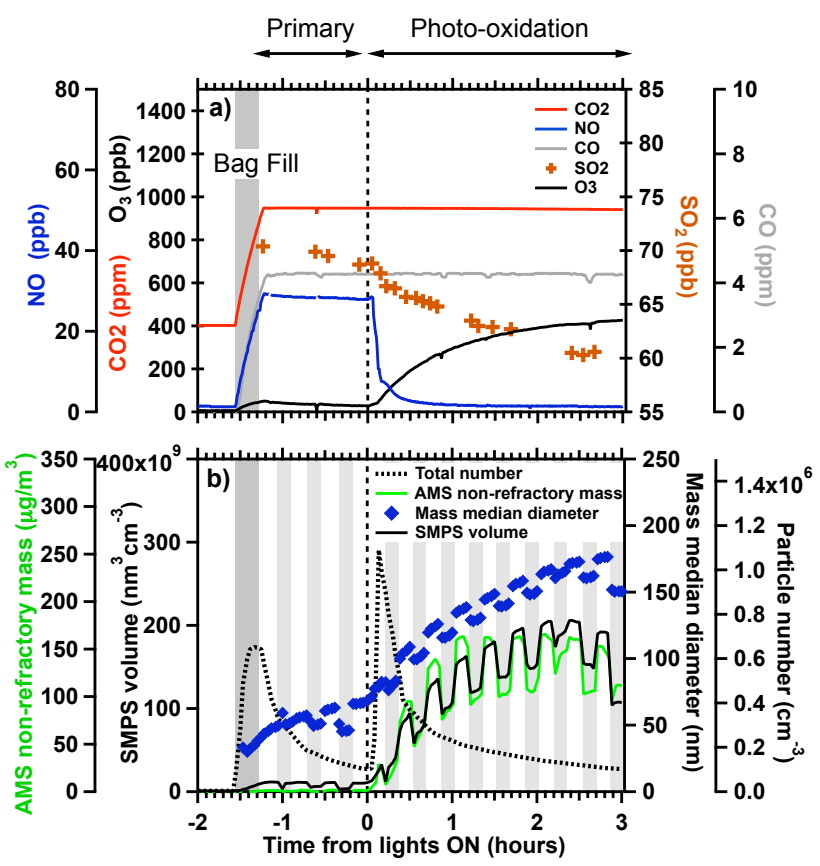

Fig. 2. Time series of (a) gas and (b) particle-phase concentrations measured during a photo-oxidation experiment conducted at $4 \%$ engine load. Vertical gray bars indicate period when bag is filled with exhaust or when the aerosol was passed through the thermodenuder.

primary characterization and photochemical aging periods. When the lights were turned on, the concentration of $\mathrm{O}_{3}$ increased, while NO decreased due to photochemistry. Photooxidation also reduced the concentration of $\mathrm{SO}_{2}$; the decay of $\mathrm{SO}_{2}$ was used to estimate $\mathrm{OH}$ concentrations inside the chamber for each experiment using an $\mathrm{OH}$ rate constant of $1.5 \times 10^{-12} \mathrm{~cm}^{3}$ molecules ${ }^{-1} \mathrm{~s}^{-1}$ (Seinfeld and Pandis, 2006). The average $\mathrm{OH}$ concentration in the experiment shown in Fig. 2 was $1.4 \times 10^{7}$ molecules $\mathrm{cm}^{-3}$, which is representative of typical summertime conditions.

Time-series of particle-phase data from the AMS and SMPS are plotted in Fig. 2b, including AMS non-refractory mass, SMPS total volume and number concentrations, and volume median diameter. The vertical gray bars in Fig. $2 b$ indicate periods when the aerosol was through the thermodenuder (TD).

Aerosol concentrations increased when exhaust was injected into the chamber. During the primary characterization phase of the experiment, the measured aerosol mass and number decreased, as particles were lost to the chamber walls (Fig. 2b). Coagulation also caused the particles to grow; the mass-weighted median diameter increased from approximately 35 to $65 \mathrm{~nm}$ over the one hour primary characterization period. After the UV lights were turned on $(t=0 \mathrm{~h})$, there was substantial secondary PM production and the particle volume median diameter grew to about $180 \mathrm{~nm}$. 
Table 1. Summary of primary PM emissions and secondary aerosol production. Uncertainty estimates are presented in parenthesis.

\begin{tabular}{l|rrr|rrr|r}
\hline & \multicolumn{3}{|c|}{ Primary PM emissions } & \multicolumn{3}{l}{ Secondary PM production @ $t=3 \mathrm{~h}$} & Ratio \\
\hline \multirow{2}{*}{ Engine load } & PM mass* & OC & EC & SOA & Sulfate & Nucleation & Primary/secondary PM ratio \\
\hline $4 \%$ & $27(12)$ & $22(9)$ & $3.0(0.5)$ & $920(170)$ & $244(15)$ & $\mathrm{Y}$ & $35(4.1)$ \\
$7 \%$ & $4.5(0.5)$ & $9.5(9)$ & $0.4(0.1)$ & $42(15)$ & $50(5)$ & $\mathrm{Y}$ & $17(2.5)$ \\
$30 \%$ & $3.0(0.3)$ & $1.5(0.4)$ & $1.8(0.2)$ & $15(8)$ & $70(25)$ & $\mathrm{Y}$ & $60(2.2)$ \\
$85 \%$ & $37(12)$ & $13(4)$ & $24(4)$ & $15(9)$ & $74(15)$ & $\mathrm{Y}$ & $2.7(1.1)$ \\
\hline
\end{tabular}

Note: all units are as $\mathrm{mg} \mathrm{kg}^{-1}$ fuel, unless otherwise noted.

Uncertainty estimates represent plus/minus of the given value. Uncertainty estimates for primary PM are standard deviation of duplicate measurements. Uncertainty estimates for secondary PM production are associated with the particle wall-loss rate, the loss of semivolatile vapors to the chamber walls $(\omega=0$ and $\omega=1)$, and the two estimates of secondary sulfate production (see text).

* PM mass is estimated using particle volume measured using SMPS measurement and assumed particle density (see text).

Evaporation inside the TD caused the particles to shrink and the measured non-refractory AMS mass and SMPS total volume concentrations to decrease.

Figure $2 b$ indicates that photo-oxidation sharply increased particle number concentrations because of nucleation inside the chamber. Figure 3 plots particle size distributions measured inside the smog chamber at four different times during this experiment. Immediately after filling, the primary PM emissions inside the chamber had a number median diameter of approximately $35 \mathrm{~nm}$, which grew to about $65 \mathrm{~nm}$ due to coagulation during the one hour primary characterization period. Immediately after turning on the lights, there was a strong nucleation burst which created a bimodal size distribution with a $20 \mathrm{~nm}$ "nucleation" mode and a larger primary mode $(\sim 75 \mathrm{~nm})$. Therefore, nucleation created an externally mixed aerosol, with a nucleation mode comprised of sulfate and organic particles and a larger mode with a primary core. The AMS p-ToF data indicate that the larger size mode is composed of both organic and sulfate particles. Photooxidation caused rapid and substantial growth in the median particle diameter of both modes. By the end of the experiments, the two modes have largely merged.

Nucleation was observed in every experiment (all engine loads) shortly after the onset of photo-oxidation $(t=0 \mathrm{~h})$. To illustrate the effect of nucleation on particle number, Fig. 4 plots time-series of the wall-loss corrected particle number enhancement ratio, which is defined as the ratio between the particle number at any point in the experiment and the particle number in the chamber during the primary characterization period. Particle nucleation events are strong, initially increasing particle concentrations in the chamber between a factor of 3 (85\% load) and 15 (30\% load). However, the particles quickly coagulate, decreasing the particle number enhancement ratio throughout the oxidation period.

To summarize the effects of photo-oxidation on PM mass across the set of experiments, Fig. 5 plots time-series of the wall-loss corrected mass inside the chamber measured at four different engine loads. All of the data are wall-loss cor-

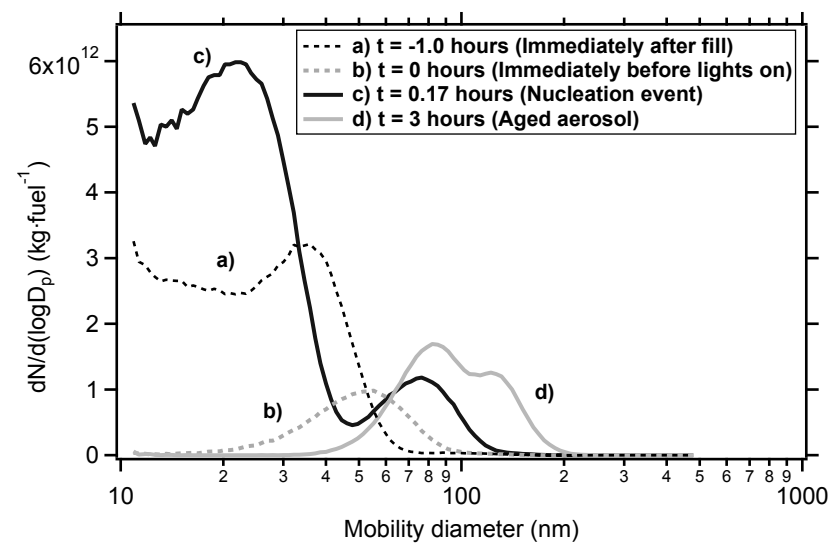

Fig. 3. Size distributions measured (a) immediately after fill, (b) immediately before lights on, (c) shortly after light on (nucleation event) (shortly after lights on), and d) aged aerosol (after $3 \mathrm{~h}$ of oxidation). The data are from a $4 \%$ load experiment. The decrease in particle number is due to a combination of coagulation and particle losses to the chamber walls.

rected assuming $\omega=0$, which provides a lower-bound estimate of the formation of secondary aerosol because it does not account for the loss of condensable vapors to the chamber walls. To quantify the relative importance of secondary $\mathrm{PM}$ production, the ratio of the secondary-to-primary $\mathrm{PM}$ is plotted on the right axis.

Photo-oxidation created substantial secondary PM mass in every experiment. At the end of the experiment, the ratio of secondary-to-primary PM mass was $35 \pm 4.1,17 \pm 2.5$, $60 \pm 2.2$, and $2.7 \pm 1.1$ for the $4,7,30$, and $85 \%$ load experiments, respectively. Therefore, secondary PM production rapidly exceeds the direct, primary particle emissions. The uncertainty estimates shown in Fig. 5 account for the uncertainty in the loss of particles and vapors to the chamber walls.

In order to compare formation of secondary PM across experiments at different engine loads, one must account for differences in hydroxyl radical $(\mathrm{OH})$ concentrations. $\mathrm{OH}$ 


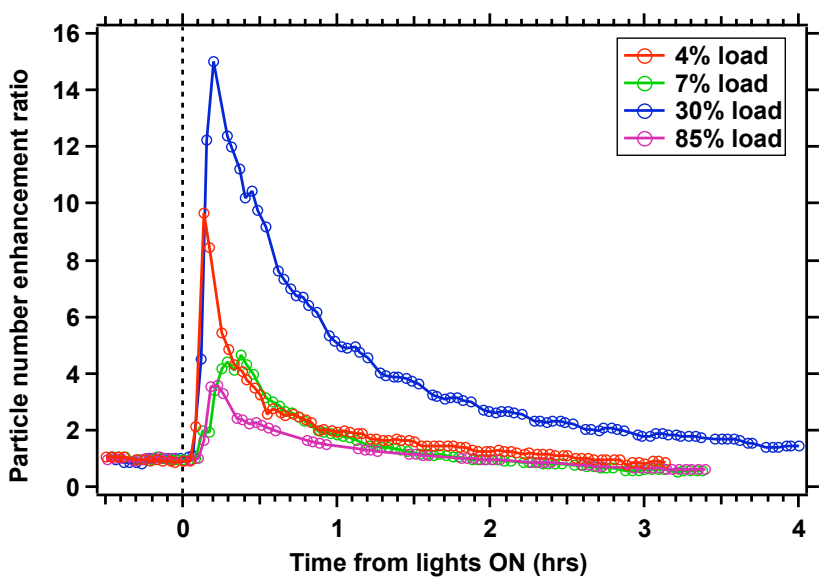

Fig. 4. Time-series of the wall-loss corrected particle number enhancement ratio for all engine loads. This ratio is defined as the ratio between the particle number at any point in the experiment and the particle number in the chamber during the primary characterization period.

concentrations were inferred from the decay of $\mathrm{SO}_{2}$ using published kinetic data. The average $\mathrm{OH}$ concentration for each experiment is listed in Table $\mathrm{S} 1$ in the Supplement. $\mathrm{OH}$ concentrations for $4 \%$ load experiments were an order of magnitude higher $\left(\sim 10^{7}\right.$ molecules $\left.\mathrm{cm}^{-3}\right)$ than for the higher load $(7,30,85 \%)$ experiments $\left(\sim 10^{6}\right.$ molecules $\left.\mathrm{cm}^{-3}\right)$. We attribute this difference to the much higher VOC concentrations in the chamber at $4 \%$ load. Therefore, several hours of oxidation for the $4 \%$ load experiment results in a greater integrated $\mathrm{OH}$ exposure $([\mathrm{OH}] \times$ time $)$ than for the higher load experiments.

The top axes on Fig. 5 indicates the $\mathrm{OH}$ exposure expressed in units of time by assuming a constant $\mathrm{OH}$ concentration of $3 \times 10^{6}$ molecules $\mathrm{cm}^{-3}$, which is a typical summertime $\mathrm{OH}$ concentration. Therefore, this axis illustrates the evolution of PM emissions on a atmospherically relevant time scale. It takes only minutes of exposure to typical summertime $\mathrm{OH}$ levels for the secondary PM concentrations to exceed the primary PM emissions at ground-idle engine load. Therefore, secondary PM production must be accounted for when assessing influence of aircraft emissions on groundlevel PM concentrations near airports.

On a fuel basis, secondary PM production was highest at $4 \%$ load and lowest at $30 \%$ load, increasing again at $85 \%$ load. The composition of secondary PM formed varied for each engine load, varying with the amount of SOA production. For emissions at $4 \%$ load, SOA formation dominated the secondary PM production (Fig. 5a). At higher loads, sulfate contributed the majority of the secondary PM mass. Since sulfate formation is a function of fuel sulfur content and $\mathrm{OH}$ exposure (and not engine load), the trends in total $\mathrm{PM}$ production are driven by differences in SOA production.
The data shown in Fig. 5 are averages of two different estimates of secondary sulfate: secondary sulfate as measured by the AMS and the decay of $\mathrm{SO}_{2}$ as measured by the $\mathrm{SO}_{2}$ monitor. We averaged these two estimates because of low signal-to-noise in the AMS in certain low concentration experiments and because very small particles $(<70 \mathrm{~nm})$ are not efficiently measured by the AMS (Liu et al., 2007). Figure 6 compares these two estimates. The solid line is the calculated sulfate formation based on measured $\mathrm{SO}_{2}$ decay. Estimates of secondary sulfate based on the AMS data are also shown, except experiments \#1 and \#2 when $\mathrm{SO}_{2}$ decay was not measured. To illustrate the uncertainty in the analysis, error bars are shown on the last measured point for each experiment. For the $4 \%$ load experiments, the sulfate estimate based on AMS data agree well with the estimate from the $\mathrm{SO}_{2}$ monitor at the end of the photo-oxidation period $\left(\mathrm{SO}_{2}\right.$ decay around $200 \mathrm{mg} \mathrm{kg}^{-1}$-fuel). For the higher load experiments (7, 30 and $85 \%$ ), the AMS estimate of sulfate was slightly higher than the $\mathrm{SO}_{2}$ monitor estimate. The significant production of secondary sulfate at each load was due to the significant sulfur content of the fuel ( $608 \mathrm{ppmw})$. One possible explanation for the differences between the estimates of secondary sulfate from the AMS and the $\mathrm{SO}_{2}$ monitor is the transmission efficiency of the AMS. The lens on the Q-AMS allows $100 \%$ transmission of particles between approximately $70-800 \mathrm{~nm}$ (Liu et al., 2007). Therefore, early in the photo-oxidation period of the experiment the AMS is sampling only a small fraction of the aerosol mass. As the particles grow into the size window of the AMS throughout the oxidation period, the agreement between the two estimates improves. The two estimates also agree with sulfate measured on filter samples collected at the end of the experiment.

Figure 7a compares the total SOA production as measured at the end of each experiment at the four different engine loads. The error bars in Fig. 7a represent the uncertainty associated with the particle wall-loss rate, the loss of semivolatile vapors to the chamber walls $(\omega=0$ and $\omega=1)$, and the two estimates of secondary sulfate production. On a fuel basis, SOA production at $4 \%$ was a factor of 20 , or more, higher than that measured at the other load conditions. The peak production was at $4 \% \mathrm{load}$ and a minimum at $30 \%$ engine load.

\subsection{Organic aerosol composition and volatility}

Figure 8 plots OA mass spectra measured using the AMS. A comparison of average primary and aged OA mass spectra from three $4 \%$ load experiments is shown in Fig. 8a. The POA mass spectrum was dominated by the $\mathrm{C}_{n} \mathrm{H}_{2 n-1}$ and $\mathrm{C}_{n} \mathrm{H}_{2 n+1}$ mass fragments, which are typical of fresh hydrocarbon-like aerosol (Zhang et al., 2005). Photooxidation increases the AMS signal at oxygenated fragments $(\mathrm{m} / \mathrm{z}, 29,43,44$, etc.) and decreases the signal in the fragments associated with the primary emissions $(\mathrm{m} / \mathrm{z} 41,55$, 57, etc.). These general trends are similar to those observed 

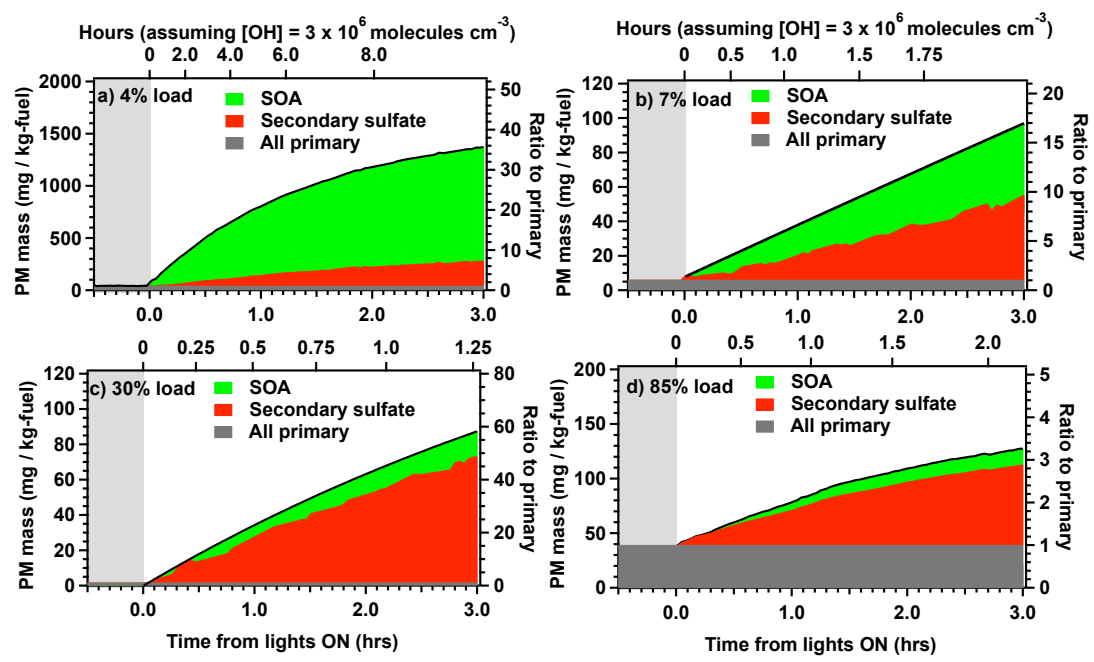

Fig. 5. Measured changes in the PM mass (secondary organics and secondary sulfate) caused by photo-oxidation for four engine loads: (a) $4 \%$ load, (b) $7 \%$ load, (c) $30 \%$ load, (d) $85 \%$ load. The data have been wall-loss corrected. Top axis indicates time for OH exposure assuming a constant $\mathrm{OH}$ concentration of $3 \times 10^{6}$ molecules $\mathrm{cm}^{-3}$. The ratio of secondary-to-primary PM mass is plotted on the right axis. Note different scales on each panel.

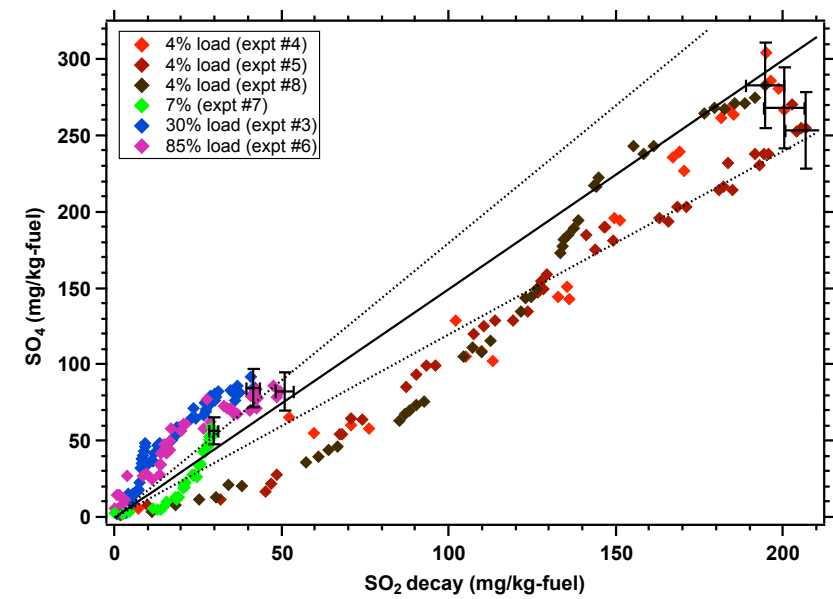

Fig. 6. Comparison of sulfate production inferred from the measured $\mathrm{SO}_{2}$ decay (x-axis) to that measured with the AMS. Perfect agreement is indicated by the solid line; the dashed lines indicate $\pm 20 \%$.

during photo-oxidation of emissions from other combustion sources (Sage et al., 2008; Grieshop et al., 2009a).

Figure $8 \mathrm{~b}$ shows the average time evolution of AMS fragments $m / z 44$ and 57 for the $4 \%$ load experiments. The AMS signal at $m / z 44\left(\mathrm{CO}_{2}^{+}\right)$is a widely used marker for the extent of oxygenation in organic aerosol (Zhang et al., 2005), while the signal at $m / z 57$ is used as a tracer for primary organic aerosol (POA) (Sage et al., 2008). The data show a dramatic change in organic aerosol composition during the first 20 min of oxidation due to SOA production, with the contribution of $f_{57}$ (fractional contribution of $\mathrm{m} / \mathrm{z} 57$ to the total
OA signal) decreasing from approximately $5 \%$ to $1.4 \%$ and the contribution of $\mathrm{m} / \mathrm{z} 44$ increasing from $6 \%$ in the POA to approximately $8.5 \%$ in the aged aerosol. After approximately 20 min of oxidation, the AMS mass spectrum of OA stops changing. At this point, the OA inside the chamber is dominated by SOA at $4 \%$ load (Fig. 5a). Even though SOA is produced throughout the experiment, the composition of the SOA (as measured with the AMS) does not appear to change.

Changes in aerosol volatility are shown in Fig. 9a, which plots OA mass fraction remaining (MFR) as a function of temperature (thermograms) for POA, aged OA, and the AMS fragments $\mathrm{m} / \mathrm{z}, 44$ and 57 for aerosol sampled at $4 \%$ engine load. The TD data indicate that both the primary and aged aircraft $\mathrm{OA}$ are semivolatile and that photo-oxidation reduces volatility of the OA. Therefore, the SOA has a lower volatility than the POA. For example at $80^{\circ} \mathrm{C}$, only about $40 \%$ of the aged OA evaporated versus about $70 \%$ of the POA. However, at lower temperatures $\left(40\right.$ and $\left.60^{\circ} \mathrm{C}\right)$ the same amount of OA evaporates from the fresh POA and SOA. Therefore the differences in volatility appear to be due to a "tail" of lower volatility material. Similar to other types of OA, the compounds that contribute to the AMS signal at $m / z 44$ are less volatile than the total OA, while the material contributing to the $\mathrm{m} / \mathrm{z} 57$ signal is more volatile. This behavior is similar to data from laboratory experiments of woodsmoke aging (Grieshop et al., 2009a) and ambient measurements (Huffman et al., 2009).

Changes in OA volatility as a function of time are shown in Fig. 9b. The figure plots the evolution of the OA MFR at $60^{\circ} \mathrm{C}$ throughout the photo-oxidation period. The dip immediately after photo-oxidation begins indicates that the initial 

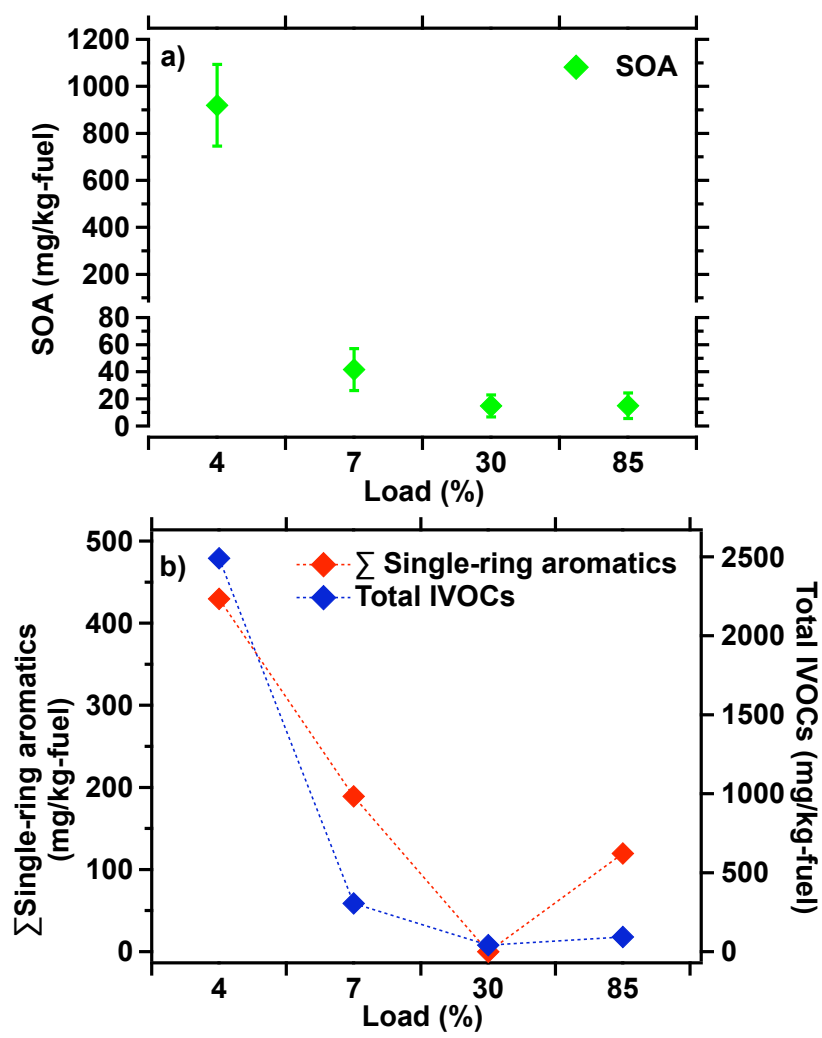

Fig. 7. (a) SOA mass measured at the end of the aging phase of the experiment. (b) Sum of single-ring aromatic compounds and sum of IVOC emissions as a function of load. Data are presented as a function of engine load. Single-ring aromatics include benzene, toluene, xylenes, ethyl benzene, styrene, ethyl toluene, and trimethylbenzenes. Sum of IVOCs includes speciated compounds and unresolved complex mixture (UCM) collected on Tenax sorbent.

SOA formed in the chamber is much less volatile than the POA or the SOA formed in the later stages of the experiment. It is interesting to note this change in volatility is the opposite of $f_{44}$ (Fig. 8b). This indicates that the low-volatility SOA formed immediately after the lights are turned on is comprised of relatively reduced compounds. As the SOA becomes more oxygenated (larger $f_{44}$ ), the MFR at $60^{\circ} \mathrm{C}$ increases to around the same value as the POA.

\subsection{Modeling secondary organic aerosol formation}

The model SOAM-II was used to investigate SOA formation, specifically to determine whether or not the measured production could be explained using traditional SOA precursors, such as single-ring aromatics and other VOCs. Before examining the model predictions, we compare the measured SOA production to SOA precursors emissions. Figure $7 \mathrm{~b}$ plots emissions of two important classes of SOA precursors: single-ring aromatics (sum of benzene, toluene, xylenes, ethyl benzene, styrene, ethyl toluene, and trimethylbenzenes)
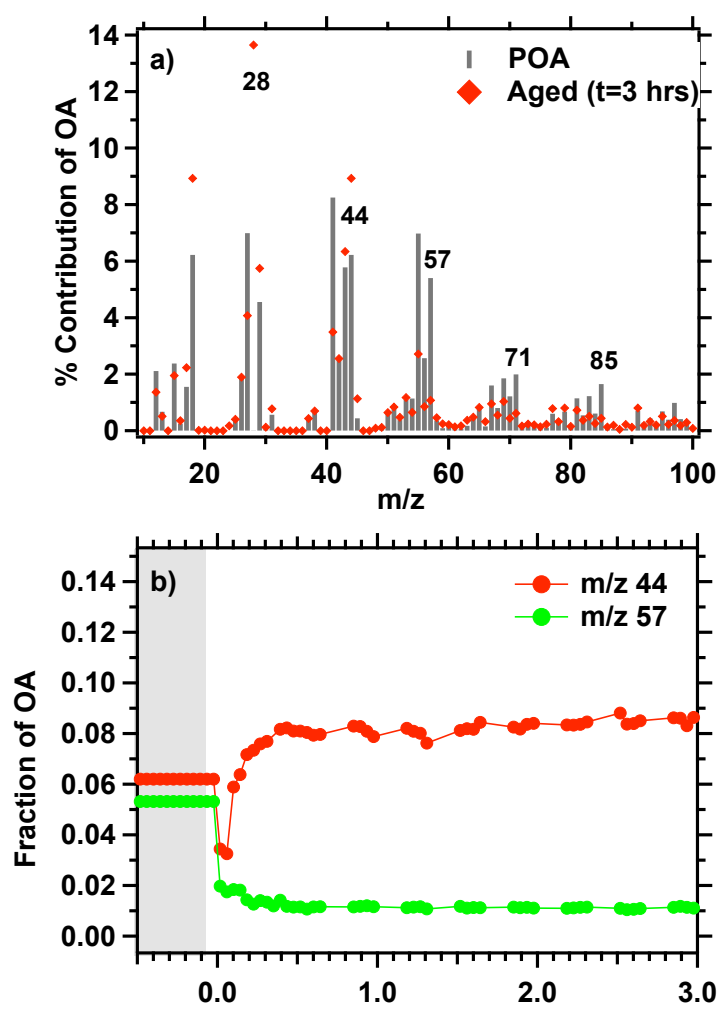

Time from lights ON (hrs)

Fig. 8. (a) Average AMS mass spectra of primary and aged OA (b) time evolution of AMS $f_{44}$ and $f_{57}$. Data are averages of all experiments conducted at $4 \%$ load. Only undenuded (no TD) data are shown.

and intermediate volatility organic compounds (IVOCs). Single-ring aromatics were measured using SUMMA canisters. Emissions of low-volatility organic vapors (species that elute from the GC column after a $\mathrm{C}_{12}$ alkane) were quantified by GC-MS analysis of samples collected on Tenax sorbent tubes. We refer to this material as intermediate volatility organic compounds (IVOCs). The vast majority ( $>90 \%$ ) of the IVOC appear as "unresolved complex mixture" or UCM that cannot be quantified on a molecular level. Therefore, we developed calibration factors for the IVOC UCM using fuel and oil samples. Details on the analysis of the IVOCs are described elsewhere (Presto et al., 2011).

The SOA production plotted in Fig. 7 qualitatively mirror the changes in SOA precursor emissions with engine load. For example, the aromatic emissions were highest at $4 \%$ load, more than a factor of two greater than the emissions at higher engine loads, consistent with previous studies (Anderson et al., 2006; Herndon et al., 2006; Agrawal et al., 2008). Although aromatics are important SOA precursors, the mass of SOA produced after three hours of photo-oxidation at $4 \%$ load is greater than the total emissions of single-ring aromatics. Therefore, photo-oxidation of single-ring aromatics by 

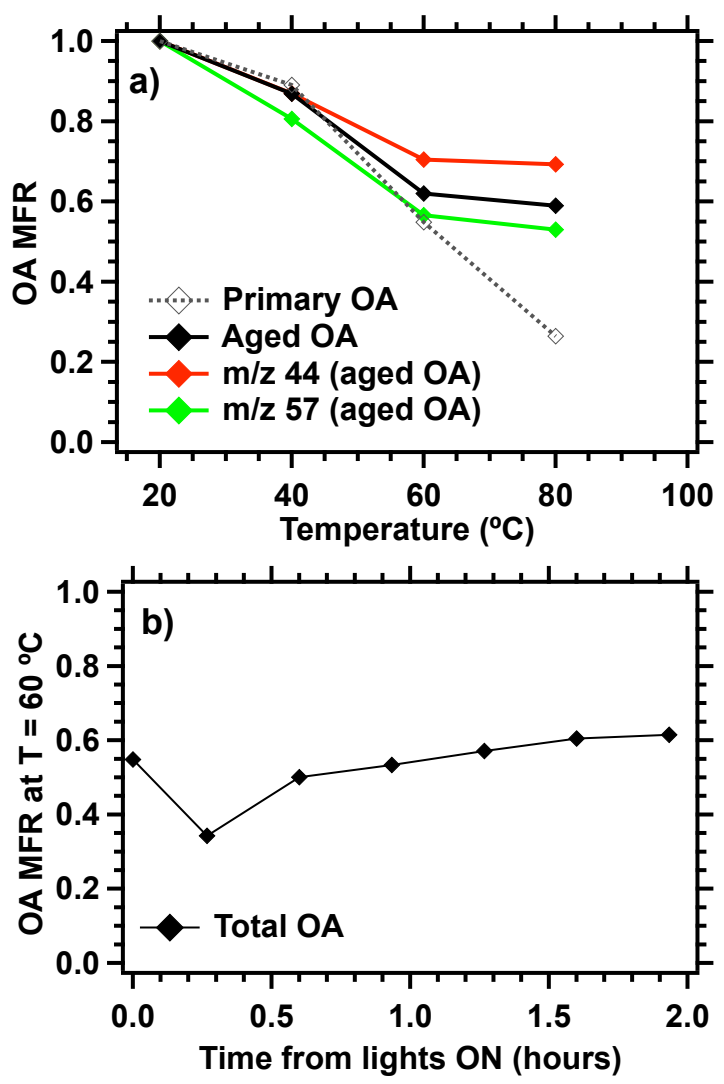

Fig. 9. Thermodenuder data: (a) average thermograms for primary OA, aged OA, and AMS fragments $\mathrm{m} / z, 44$ and 57 for the aged aerosol (b) evolution of total OA volatility at $T=60^{\circ} \mathrm{C}$ during the photo-oxidation phase of the experiment. Data are from a $4 \%$ engine load experiment. Lines are included to help guide the eye.

themselves cannot to explain the measured SOA production (unless all of the single-ring aromatics were completely oxidized during the photo-oxidation phase of the experiment and the SOA yields from these compounds were greater than $100 \%)$. At $85 \%$ load, the emissions of single-ring aromatics are higher than the mass of SOA produced by a factor of $\sim 8$. Therefore, aromatics could plausibly explain the SOA in that experiment. Figure $7 \mathrm{~b}$ indicates that the emissions of IVOCs exceed the SOA mass at every load.

To quantify the fraction of SOA formation that can be explained by traditional SOA precursors, Fig. 10 plots the predictions for SOA formation at (a) $4 \%$ and (b) $85 \%$ engine load using the model SOAM-II and the measured aromatic, olefin, and alkane concentrations. The dashed area indicates the range of SOA estimates including uncertainty in wall-loss corrections. SOA formation depends on VOC-to- $\mathrm{NO}_{\mathrm{x}}$ ratios, which varied as a function of load. At $4 \%$ load, the initial $\mathrm{VOC} / \mathrm{NO}_{\mathrm{x}}$ was greater than $7 \mathrm{ppbC} \mathrm{ppb}^{-1}-\mathrm{NO}_{\mathrm{x}}$, so low$\mathrm{NO}_{\mathrm{x}}$ yields were used in SOAM-II. At $85 \%$ load, the initial $\mathrm{VOC} / \mathrm{NO}_{\mathrm{x}}$ was $<0.01 \mathrm{ppbC} \mathrm{ppb}^{-1}-\mathrm{NO}_{\mathrm{x}}$, so high- $\mathrm{NO}_{\mathrm{x}}$ yields were used in SOAM-II.
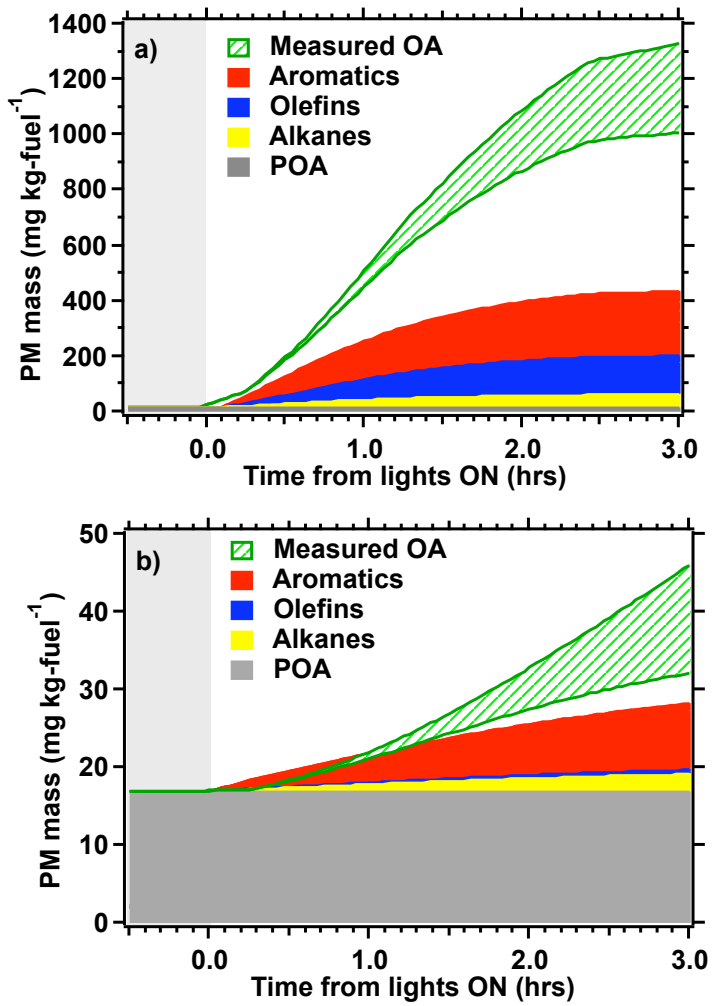

Fig. 10. Comparisons of predicted and measured SOA at (a) $4 \%$ engine load and (b) $85 \%$ engine load. Dashed area represents range of measured SOA estimates and accounts for uncertainty in wallloss corrections. Different colored areas indicate contributions of aromatic, olefin, and alkane precursors to the predicted SOA.

At both high and low load, SOAM-II under-predicts the extent of SOA formation measured in the chamber based on the large suite of traditional precursors listed in Table S4. For example, after $3 \mathrm{~h}$ of oxidation, SOAM-II can only explain $\sim 40 \%$ of the measured SOA for the $4 \%$ load experiment and $\sim 60 \%$ of the measured SOA for the $85 \%$ load experiment. The predicted SOA for the $4 \%$ load experiment (Fig. 10a) is dominated by SOA from aromatic precursors, with small but significant contributions from olefins and alkanes. At $85 \%$ load (Fig. 10b), the predicted SOA is dominated by SOA formed from aromatic precursors with even smaller contribution from olefins and alkanes. However, SOAM-II may over-predict the contribution of the olefins to the total SOA formation because the lumping scheme used by SOAM-II includes some very low molecular weight olefins, such as 1-butene and 1,3-butadiene. These species are unlikely to form SOA with yields and partitioning coefficients assigned by the model. Additionally, the model uses the highest published yield data available for the mono-aromatic compounds. Therefore, the results shown here represent an upper bound on the modeled SOA estimates based on traditional precursors. 
Although SOAM-II cannot explain the measured SOA production, it does not account for emissions of IVOCs and other less-volatile organic species. As shown in Fig. 7b, the emissions of IVOCs are very substantial, exceeding the SOA production. Therefore, from a simple mass balance perspective photo-oxidation of IVOCs may be an important source of SOA. A future manuscript will investigate the potential contribution of IVOCs to the measured SOA formation.

\section{Discussion and conclusions}

Smog chamber experiments indicate that photo-oxidation of aircraft emissions produces significant amounts of secondary PM, which, under typical summertime conditions, exceed the primary emissions within minutes of the exhaust leaving the engine. Therefore, secondary PM must be considered when evaluating the influence of aircraft emissions on local and regional air quality. These results also contribute to our growing understanding of the dynamic nature of PM emissions from combustion systems (Grieshop et al., 2009a; Chirico et al., 2010).

The amount and composition of the secondary PM varies for each engine load. Secondary PM production was highest at ground-idle (4\% load) and minimum at approach $(30 \%$ load). At $4 \%$ load, the secondary PM was dominated by SOA while at higher loads it was dominated by secondary sulfate. Secondary sulfate production was consistently high across all engine loads due to the relatively high sulfur content of the fuel. Reducing fuel sulfur levels will reduce the formation of secondary aerosol. However, reducing the fuel sulfur levels, even to trace levels, would not alter the conclusion that secondary PM production dominates primary emissions, as the production of SOA exceeded the primary PM mass emissions, especially at low engine loads.

Oxidation of traditional SOA precursors cannot explain the extent of SOA formation observed. This provides further evidence of the importance of non-traditional precursors. Aircraft engines emit substantial amounts of low-volatility organics, which creates a significant pool of SOA precursors that are not accounted for in traditional SOA models and traditional emissions data (Robinson et al., 2010). Very high SOA formation was observed at the lowest engine loads, which correspond to ground-idle operation conditions. The results suggest that SOA formation from aircraft could have a substantial impact on ground-level PM concentrations near airports. However, the failure of SOAM-II to explain the measured SOA production indicates that existing chemical transport models such as CMAQ likely under-predict the impact of aircraft emissions on local and regional PM levels.

\section{Supplementary material related to this article is available online at: http://www.atmos-chem-phys.net/11/4135/2011/ acp-11-4135-2011-supplement.pdf.}

Acknowledgements. Funding was provided by the US Department of Defense Strategic Environmental Research and Development Program (SERDP) under project WP-1626. This project would not have been possible without the support of the 171st Air Refueling Wing. Many individuals from the 171st contributed to the project, but we owe special thanks to those from the Maintenance Group and Civil Engineering. Key contributors included James Weber, Rich Kelly, and Karen Knoerdel. Pat Gallagher and Jeff Andrulonis. The views, opinions, and/or findings contained in this paper are those of the authors and should not be construed as an official position of any of the funding agencies.

Edited by: H. Saathoff

\section{References}

Agrawal, H., Sawant, A. A., Jansen, K., Wayne Miller, J., and Cocker, D. R.: Characterization of chemical and particulate emissions from aircraft engines, Atmos. Environ., 42, 43804392, 2008.

Aiken, A. C., Decarlo, P. F., Kroll, J. H., Worsnop, D. R., Huffman, J. A., Docherty, K. S., Ulbrich, I. M., Mohr, C., Kimmel, J. R., Sueper, D., Sun, Y., Zhang, Q., Trimborn, A., Northway, M., Ziemann, P. J., Canagaratna, M. R., Onasch, T. B., Alfarra, M. R., Prevot, A. S., Dommen, J., Duplissy, J., Metzger, A., Baltensperger, U., and Jimenez, J. L.: O/c and om/oc ratios of primary, secondary, and ambient organic aerosols with high-resolution time-of-flight aerosol mass spectrometry, Environ. Sci. Technol., 42, 4478-4485, 2008.

Allan, J. D., Delia, A. E., Coe, H., Bower, K. N., Alfarra, M. R., Jimenez, J. L., Middlebrook, A. M., Drewnick, F., Onasch, T. B., Canagaratna, M. R., Jayne, J. T., and Worsnopf, D. R.: A generalised method for the extraction of chemically resolved mass spectra from aerodyne aerosol mass spectrometer data, J. Aerosol Sci., 35, 909-922, doi:10.1016/J.Jaerosci.2004.02.007, 2004.

An, W. J., Pathak, R. K., Lee, B.-H., and Pandis, S. N.: Aerosol volatility measurement using an improved thermodenuder: Application to secondary organic aerosol, J. Aerosol Sci., 38, 305314, 2007.

Anderson, B. E., Chen, G., and Blake, D. R.: Hydrocarbon emissions from a modern commercial airliner, Atmos. Environ., 40, 3601-3612, 2006.

Carslaw, D. C., Beevers, S. D., Ropkins, K., and Bell, M. C.: Detecting and quantifying aircraft and other on-airport contributions to ambient nitrogen oxides in the vicinity of a large international airport, Atmos. Environ., 40, 5424-5434, 2006.

Chan, A. W. H., Kautzman, K. E., Chhabra, P. S., Surratt, J. D., Chan, M. N., Crounse, J. D., Kürten, A., Wennberg, P. O., Flagan, R. C., and Seinfeld, J. H.: Secondary organic aerosol formation from photooxidation of naphthalene and alkylnaphthalenes: implications for oxidation of intermediate volatility organic compounds (IVOCs), Atmos. Chem. Phys., 9, 3049-3060, doi:10.5194/acp-9-3049-2009, 2009. 
Chirico, R., DeCarlo, P. F., Heringa, M. F., Tritscher, T., Richter, R., Prévôt, A. S. H., Dommen, J., Weingartner, E., Wehrle, G., Gysel, M., Laborde, M., and Baltensperger, U.: Impact of aftertreatment devices on primary emissions and secondary organic aerosol formation potential from in-use diesel vehicles: results from smog chamber experiments, Atmos. Chem. Phys., 10, 11545-11563, doi:10.5194/acp-10-11545-2010, 2010.

DeCarlo, P., Slowik, J., Worsnop, D., Davidovits, P., and Jimenez, J.: Particle morphology and density characterization by combined mobility and aerodynamic diameter measurements. Part 1 : Theory, Aerosol Sci. Technol., 38, 1185-1205, 2004.

Dodson, R. E., Andres Houseman, E., Morin, B., and Levy, J. I.: An analysis of continuous black carbon concentrations in proximity to an airport and major roadways, Atmos. Environ., 43, 37643773, 2009.

Grieshop, A. P., Donahue, N. M., and Robinson, A. L.: Laboratory investigation of photochemical oxidation of organic aerosol from wood fires 2: analysis of aerosol mass spectrometer data, Atmos. Chem. Phys., 9, 2227-2240, doi:10.5194/acp-9-2227-2009, 2009a.

Grieshop, A. P., Logue, J. M., Donahue, N. M., and Robinson, A. L.: Laboratory investigation of photochemical oxidation of organic aerosol from wood fires 1: measurement and simulation of organic aerosol evolution, Atmos. Chem. Phys., 9, 1263-1277, doi:10.5194/acp-9-1263-2009, 2009b.

Herndon, S. C., Rogers, T., Dunlea, E. J., Jayne, J. T., Miake-Lye, R., and Knighton, B.: Hydrocarbon emissions from in-use commercial aircraft during airport operations, Environ. Sci. Technol., 40, 4406-4413, doi:10.1021/es0512091, 2006.

Herndon, S. C., Wood, E. C., Northway, M. J., Miake-Lye, R., Thornhill, L., Beyersdorf, A., Anderson, B. E., Dowlin, R., Dodds, W., and Knighton, W. B.: Aircraft hydrocarbon emissions at oakland international airport, Environ. Sci. Technol., 43, 1730-1736, doi:10.1021/es801307m, 2009.

Hildebrandt, L., Donahue, N. M., and Pandis, S. N.: High formation of secondary organic aerosol from the photo-oxidation of toluene, Atmos. Chem. Phys., 9, 2973-2986, doi:10.5194/acp-92973-2009, 2009.

Hu, S., Fruin, S., Kozawa, K., Mara, S., Winer, A. M., and Paulson, S. E.: Aircraft emission impacts in a neighborhood adjacent to a general aviation airport in southern california, Environ. Sci. Technol., 43, 8039-8045, 10.1021/es900975f, 2009.

Huffman, J. A., Ziemann, P. J., Jayne, J. T., Worsnop, D. R., and Jimenez, J. L.: Development and characterization of a fast-stepping/scanning thermodenuder for chemically-resolved aerosol volatility measurements, Aerosol Sci. Technol., 42, 395407, 2008.

Huffman, J. A., Docherty, K. S., Aiken, A. C., Cubison, M. J., Ulbrich, I. M., DeCarlo, P. F., Sueper, D., Jayne, J. T., Worsnop, D. R., Ziemann, P. J., and Jimenez, J. L.: Chemically-resolved aerosol volatility measurements from two megacity field studies, Atmos. Chem. Phys., 9, 7161-7182, doi:10.5194/acp-9-71612009, 2009.

Kinsey, J. S., Dong, Y., Williams, D. C., and Logan, R.: Physical characterization of the fine particle emissions from commercial aircraft engines during the aircraft particle emissions experiment (apex) 1-3, Atmos. Environ., 44, 2147-2156, 2010.

Liu, P. S. K., Deng, R., Smith, K. A., Williams, L. R., Jayne, J. T., Canagaratna, M. R., Moore, K., Onasch, T. B.,
Worsnop, D. R., and Deshler, T.: Transmission efficiency of an aerodynamic focusing lens system: Comparison of model calculations and laboratory measurements for the aerodyne aerosol mass spectrometer, Aerosol Sci. Technol., 41, 721-733, doi:10.1080/02786820701422278, 2007.

Matsunaga, A. and Ziemann, P.: Gas-wall partitioning of organic compounds in a teflon film chamber and potential effects on reaction product and aerosol yield measurements, Aerosol Sci. Technol., 44, 881-892, 2010.

Murphy, B. N. and Pandis, S. N.: Simulating the formation of semivolatile primary and secondary organic aerosol in a regional chemical transport model, Environ. Sci. Technol., 43, 47224728, doi:10.1021/es803168a, 2009.

Ng, N. L., Kroll, J. H., Chan, A. W. H., Chhabra, P. S., Flagan, R. C., and Seinfeld, J. H.: Secondary organic aerosol formation from m-xylene, toluene, and benzene, Atmos. Chem. Phys., 7, 3909-3922, doi:10.5194/acp-7-3909-2007, 2007.

Odum, J. R., Hoffmann, T., Bowman, F., Collins, D., Flagan, R. C., and Seinfeld, J. H.: Gas/particle partitioning and secondary organic aerosol yields, Environ. Sci. Technol., 30, 2580-2585, doi:10.1021/es950943+, 1996.

Onasch, T. B., Jayne, J. T., Herndon, S., Worsnop, D. R., MiakeLye, R. C., Mortimer, I. P., and Anderson, B. E.: Chemical properties of aircraft engine particulate exhaust emissions, Journal of Propulsion and Power, 25, 1121-1137, doi:10.2514/1.36371, 2009.

Petzold, A. and Schröder, F. P.: Jet engine exhaust aerosol characterization, Aerosol Sci. Technol., 28, 62-76, 1998.

Presto, A. A., Nguyen, N., Ranjan, M., Reeder, A., Lipsky, E. M., Hennigan, C. J., Miracolo, M. A., and Robinson, A. L.: Fine particle and organic vapor emissions from staged tests of an in-use aircraft engine, Atmos. Environ, doi:10.1016/j.atmosenv.2011.03.061, in press, 2011.

Robinson, A. L., Grieshop, A. P., Donahue, N. M., and Hunt, H. W.: Updating our conceptual model for fine particle mass emissions from combustion systems, J. Air Waste Manage. Assoc., 60, 1204-1222, 2010.

Sage, A. M., Weitkamp, E. A., Robinson, A. L., and Donahue, N. M.: Evolving mass spectra of the oxidized component of organic aerosol: results from aerosol mass spectrometer analyses of aged diesel emissions, Atmos. Chem. Phys., 8, 1139-1152, doi:10.5194/acp-8-1139-2008, 2008.

Seinfeld, J. H. and Pandis, S. N.: Atmospheric chemistry and physics: from Air Pollution to Climate Change, John Wiley, New York, USA, 1185, 2006

Slemr, F., Giehl, H., Slemr, J., Busen, R., Schulte, P., and Haschberger, P.: In-flight measurement of aircraft non-methane hydrocarbon emission indices, Geophys. Res. Lett., 25, 321-324, doi:10.1029/97gl03784, 1998.

Spicer, C. W., Holdren, M. W., Riggin, R. M., and Lyon, T. F.: Chemical composition and photochemical reactivity of exhaust from aircraft turbine engines, Ann. Geophys., 12, 944-955, doi:10.1007/s00585-994-0944-0, 1994.

Unal, A., Hu, Y., Chang, M. E., Talat Odman, M., and Russell, A. G.: Airport related emissions and impacts on air quality: Application to the atlanta international airport, Atmos. Environ., 39, 5787-5798, 2005.

Weitkamp, E. A., Sage, A. M., Pierce, J. R., Donahue, N. M., and Robinson, A. L.: Organic aerosol formation from photochemi- 
cal oxidation of diesel exhaust in a smog chamber, Environ Sci Technol, 41, 6969-975, 2007.

Wood, E. C., Herndon, S. C., Timko, M. T., Yelvington, P. E., and Miake-Lye, R. C.: Speciation and chemical evolution of nitrogen oxides in aircraft exhaust near airports, Environ. Sci. Technol., 42, 1884-1891, doi:10.1021/es072050a, 2008.

Yu, K. N., Cheung, Y. P., Cheung, T., and Henry, R. C.: Identifying the impact of large urban airports on local air quality by nonparametric regression, Atmos. Environ., 38, 4501-4507, 2004.
Zhang, Q., Alfarra, M. R., Worsnop, D. R., Allan, J. D., Coe, H., Canagaratna, M. R., and Jimenez, J. L.: Deconvolution and quantification of hydrocarbon-like and oxygenated organic aerosols based on aerosol mass spectrometry, Environ. Sci. Technol., 39, 4938-4952, 2005. 